British Journal of Psychiatry (1994), 164, 847-854

\title{
Correspondence
}

Contents: Association between sexual and substance abuse/Treatment of catatonia with intravenous biperidene/Debt and deliberate self-harm/ Risk of HIV for women who inject drugs/ Dysphagia in the neuroleptic malignant syndromel Clozapine-induced neutropenia-or not/Administrative problems limiting electroconvulsive therapy/B37 repeats are normal in most schizophrenic patients/Fluvoxamine-prescription event monitoring/Death during alcohol withdrawal/ Glucocorticoids and the genesis of depressive illness/SSRIs to treat sexual dysfunction.

\section{Association between sexual and substance abuse}

SIR: Mullen et al (BJP, December 1993, 163, 721732) in a community study of women again find an association between sexual abuse and various forms of psychopathology including drug and alcohol abuse. Research in the US with young substance abusers showed that up to $75 \%$ gave a history of abuse (Rohsenow, 1988). There appears to be no comparable British research.

A small study on opiate addicts at a detoxification unit in London was performed to estimate the prevalence of a history of sexual abuse. Forty consecutive admissions were asked about sexual abuse during the routine medical interview. The sample consisted of 22 men and 18 women aged between 18 and 41 .

Fifteen subjects (36\%; 6 men and 9 women) had been victims of sexual abuse that involved genital contact of some sort. Two women had been severely and persistently abused by their fathers from the age of six. Three women had been raped in early adolescence (age 12-14) by acquaintances. Two women had had 'consensual' underage sexual intercourse with older men starting at age 12 and 14 . There were two cases of genital fondling in childhood by male relatives. Among the men, three of the six described severe abuse involving violence occurring at age 12 or under. The other cases were genital fondling by older boys or men.

In Mullen et al's recent survey of women $20 \%$ of the total sample report sexual abuse involving genital contact of some degree and 3\% report actual intercourse. This compares with rates of $50 \%$ and $39 \%$ for the female opiate addicts studied.

These data suggest that a history of sexual abuse may be much more common among people with severe drug problems than among the general population. A larger study with an appropriate control group would be needed to clarify this. It also demonstrates that sexual abuse is a diverse phenomenon and is likely to have a complex relationship with substance abuse.

Rohsenow, D., Corbett, R. \& Devine, D. (1988) Molested as children: a hidden contribution to substance abuse? Journal of Substance Abuse Treatment, 5, 13-18.

Springfield Hospital

JoANNA MONCRIEFF

61 Glenburnie Road

London SWI7 7DJ

\section{Treatment of catatonia with intravenous biperidene}

SIR: Stuporous catatonias are usually treated with high doses of potent neuroleptics or by electroconvulsive therapy. Treatment with neuroleptics may cause severe side-effects like the neuroleptic malignant syndrome, which may be similar to catatonic symptoms. Recently successful treatment of catatonic states with lorazepam was reported (Salam \& Kilzieh, 1988), but the danger of respiratory depression limits the benefits of this therapeutic strategy.

Encouraged by reported observations (Winter \& Grosse, 1979; Hirschberg, 1964), we treated two patients with catatonic stupor with intravenous (i.v.) biperidene. Prompt and impressive improvement of clinical symptoms was observed after single doses of 5-15 mg. Therefore, we studied the effect of biperidene in an open prospective study in 11 consecutive patients with catatonic stupor. All subjects were in-patients of a psychiatric hospital. They were treated with $5 \mathrm{mg}$ biperidene i.v., given every $30 \mathrm{~min}$ up to $15 \mathrm{mg}$. Lack of response required crossing-over to 3 days $60 \mathrm{mg}$ haloperidol per day and recrossing-over to biperidene subsequently. Exclusion criteria were organic mental disorders, 